\title{
A DNA flu vaccine in practice
}

To the editor:

The commentary by Gareth Forde on the use of DNA vaccines to combat influenza published in the September issue (Nat. Biotechnol. 23, 1059-1062, 2005) raises two crucial issues: how to produce enough pharmaceutical grade material, and how to deliver enough DNA to induce protective immunity.

For a DNA vaccine to meet the health crisis of the emergence of a potentially virulent and communicable influenza strain arising from $\mathrm{H} 5 \mathrm{~N} 1$, kilogram quantities of pharmaceutical grade material would be required. I know of only one or two companies that have this kind of potential.

My group has analyzed whether existing production plants for producing biopharmaceutical proteins, and some antibiotic plants, could be used in the event of an emergency, such as an imminent influenza pandemic. The results, which embrace our research on DNA largescale processing and those of the other main groups in the field, are published in Biotechnology Progress (21, 1577-1592, 2005) and suggest that though challenging, it should be possible. However, transfer of the technology would take time and there are major intellectual property issues.

The second challenge, achieving an effective human response with reasonable doses of DNA, might be achieved by innovative delivery technology. The UK company PowderMed, for example, showed promising results for an influenza DNA vaccine in a phase 1 trial in 2004 and is now conducting phase 2 trials.

\section{Peter Dunnill}

The Advanced Centre for Biochemical Engineering, Department of Biochemical Engineering, University College London, Torrington Place, London WC1E 7JE, UK. e-mail:p.dunnill@ucl.ac.uk

\section{Sequencing thoroughbreds}

\section{To the editor:}

A news story by Jim Kling that appeared in the November issue is timely and well researched (Nat. Biotechnol. 23, 13331335, 2005); however, two points merit clarification.

Kling suggests that the 'polony' sequencing method developed by my group at Harvard and collaborators at Washington University ${ }^{1}$

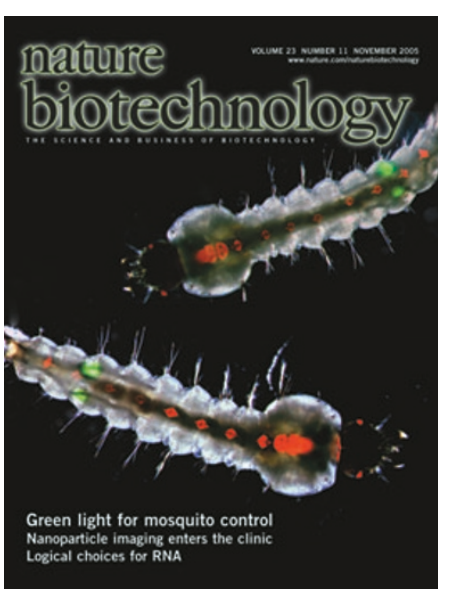

$\mathrm{kbp}$ (at an error rate of $\left.4.0 \times 10^{-5}\right)$. Sanger/ABI is $\$ 7 / \mathrm{kbp}$ (at an error rate of $\left.4 \times 10^{-6}\right)$. Both methods can achieve trade-offs between cost and accuracy, but published data does not yet indicate any point where 454 is less costly than Sanger for a given accuracy goal. We estimate polony sequencing at $\$ 0.8$ per consensus bp ( $\$ 0.11 /$ rawbp, ref. 1). More detailed “avoids potentially costly PCR.” In fact, our method does not completely 'avoid' PCR; it merely attempts to use less of the costly PCR enzymes by using beads 20,000 times smaller in volume than those used in the method of the 454 group (ref. 2).

The article also states that " 454 estimates that it achieved a 100-fold decrease in cost compared with the Sanger method." This is quite different from " 100 -fold increase in throughput," which is what they reported in their Nature paper. The 454 cost was $\$ 5,000$ for a $580-\mathrm{kbp}$ genome or $\$ 9$ per consensus cost-accuracy trade-off analyses are to be encouraged and a possible start point is available here: http://arep.med.harvard. edu/Polonator/speed.html.

George Church, Jay Shendure \& Greg Porreca Harvard Medical School, NRB room 238, 77 Avenue Louis Pasteur, Boston, Massachusetts 02115, USA.

e-mail: arep.med.harvard.edu/gmc

1. Shendure, J. et al. Science 309, 1728-1732 (2005).

2. Margulies, M. et al. Nature 437, 376-380 (2005). 